\title{
Perbandingan Efektivitas dan Keamanan Kombinasi Ketamin/Midazolam Dibandingkan Ketamin Tunggal sebagai Sedasi pada Anak
}

\author{
Murti Andriastuti, ${ }^{*}$ Dewi Kartika S, ${ }^{*}$ Andi Ade Wijaya Ramlan** \\ ${ }^{*}$ Departemen Ilmu Kesehatan Anak Fakultas Kedokteran Universitas IndonesiaI/RS Cipto Mangunkusumo, Jakarta \\ **Departemen Anestesi, Fakultas Kedokteran Universitas Indonesia/RS.Cipto Mangunkusumo, Jakarta
}

Latar belakang. Penambahan midazolam sebelum pemberian ketamin sebagai obat sedasi pada tindakan aspirasi sumsum tulang atau pemberian kemoterapi intratekal terbukti meningkatkan efektivitas sedasi, mengurangi ansietas dan mengurangi efek samping ketamin yaitu mimpi buruk, halusinasi, dan fenomena pulih sadar pasca pemberian ketamin.

Tujuan. Membandingkan efektivitas dan keamanan sedasi antara kombinasi ketamin/midazolam dan ketamin tunggal berdasarkan bukti ilmiah.

Metode. Penelusuran pustaka database elektronik melalui Pubmed, Clinical Key, dan Google Scholar.

Hasil. Suatu uji klinis acak tersamar mendapatkan awitan sedasi secara signifikan lebih singkat pada kelompok ketamin/midazolam dibandingkan ketamin yaitu 2,6 menit dan 3,4 menit (nilai $\mathrm{p}=0,01$ ). Jumlah subjek yang mengalami amnesia total pada kelompok ketamin/midazolam dibandingkan ketamin yaitu 100\% dan 80,3\% (p=0,001). Kejadian mimpi buruk pada kelompok ketamin/ midazolam dibandingkan ketamin 6,3\% dan 19,6\% (p=0,04). Lima uji kohort menunjukkan kombinasi ketamin/midazolam dapat menjadi pilihan sedasi yang cepat, efektif, dan aman bagi anak yang akan menjalani berbagai tindakan di bidang hematologi-onkologi. Kombinasi ini aman dan efisien untuk mengurangi nyeri selama prosedur dan mengurangi kecemasan pasien dan orangtua.

Kesimpulan. Berdasarkan penelitian ilmiah yang telah dipaparkan, penambahan midazolam pada ketamin tidak menambah efek samping, dan kombinasi ini lebih baik dibandingkan ketamin tunggal. Sari Pediatri 2016;18(3):240-4

Kata kunci : ketamin, midazolam, sedasi, anak

\section{The Efficacy and Safety of Sedation Using Midazolam and Ketamine Combination to a Single Ketamine Based on Scientific Evidence}

Murti Andriastuti, ${ }^{*}$ Dewi Kartika S,* Andi Ade Wijaya Ramlan**

Background. Several studies have shown that the addition of midazolam on ketamine sedation can increase effectiveness, reduce anxiety and reduce side effects of ketamine in the form of nightmare, hallucinations, and agitation emergence.

Objective. To compare the efficacy and safety of sedation using midazolam and ketamine combination to a single ketamine based on scientific evidence.

Methods. Literature search use the electronic databases: Pubmed, Clinical Key and Google Scholar.

Results. A randomized clinical trial showed that onset of sedation was significantly shorter in the combination compare to single ketamine group (2.6 vs 3.4 minutes, $\mathrm{p}=0.01)$. The number of subjects who experienced total amnesia in ketamine/midazolam compare to single ketamine group was $100 \%$ and $80.3 \%(\mathrm{p}=0.001)$. Nightmare / crying spells in combination compare to single ketamine group was $6.3 \%$ and $19.6(\mathrm{p}=0.04)$. Five cohort showed a combination of ketamine and midazolam sedation may be an option that is fast, effective, and safe for children who will undergo various actions in the field of hematology-oncology. This combination is a safe and efficient method to reduce pain during the procedure and reduce anxiety of patients and parents.

Conclusion. Based on scientific research that has been presented, the addition of midazolam on ketamine does not add to the side effects, and this combination is superior to single ketamine. Sari Pediatri 2016;18(3):240-4

Keywords: ketamine, midazolam, sedation, children

Alamat korespondensi: DR. Dr. Murti Andriastuti, SpA(K). Departemen Ilmu Kesehatan Anak Fakultas Kedokteran Universitas IndonesiaI-RS Cipto Mangunkusumo, Jakarta. Email: murtiandri@yahoo.com 
S aat ini belum ada pedoman yang mengatur secara spesifik pemberian sedasi pada tindakan invasif yang akan dilakukan oleh tiap spesialistik. ${ }^{1}$ Sedasi dengan pemberian kombinasi ketamin/ midazolam digunakan oleh beberapa Pusat HematologiOnkologi Anak dapat mengurangi trauma fisik dan psikologis pada prosedur invasif, baik untuk pasien, orangtua, maupun dokter dan dapat meningkatkan kesuksesan prosedur. ${ }^{2}$ Berdasarkan hal tersebut maka diajukan pertanyaan klinis sebagai berikut, "Bagaimanakah manfaat dan keamanan sedasi kombinasi ketamin/ midazolam intravena dibandingkan sedasi ketamin tunggal pada pasien anak yang akan menjalani tindakan aspirasi sumsum tulang dan kemoterapi intratekal?”

\section{Kasus}

Anak perempuan, usia 9 tahun didampingi orangtua berobat ke Poliklinik Hematologi-Onkologi IKA RSCM berdasarkan rujukan dari Rumah Sakit Umum Daerah (RSUD) Bekasi dengan keterangan tersangka leukemia. Terdapat keluhan penurunan berat badan, lemas, pucat, dan nyeri tulang. Pemeriksaan fisis saat datang di RSCM ditemukan hepatomegali dan splenomegali. Pemeriksaan laboratorium gambaran darah tepi menunjukkan pansitopenia serta ditemukan sel blas. Pemeriksaan aspirasi sumsum tulang sesuai dengan leukemia limfoblastik akut lineage-1 (LLA L1). Hasil pemeriksaan pungsi lumbal tidak menunjukkan infiltrasi ke sistem saraf pusat (SSP). Pasien direncanakan untuk menjalani protokol kemoterapi LLA risiko tinggi. Saat menjalani prosedur aspirasi sumsum tulang, setelah pemberian ketamin dosis pertama pasien mengalami halusinasi dan gelisah, sehingga membutuhkan pemberian ulangan ketamin dosis kedua. Pasca tindakan pasien masih tampak gelisah, tidak mengenali dokter maupun ibunya, serta mengucapkan kata-kata kasar. Pasien mengalami hal tersebut selama satu jam pasca tindakan sehingga menimbulkan kekhawatiran orangtua. Orangtua dan pasien merasakan trauma setiap kali akan dilakukan tindakan aspirasi sumsum tulang dan pemberian kemoterapi intratekal terhadap pasien.

\section{Metode penelusuran literatur}

Untuk menjawab pertanyaan klinis, dilakukan penelusuran pustaka secara online menggunakan database elektronik Pubmed, Clinical Key dan Google Scholar dengan menggunakan batasan uji klinik pada manusia dengan pengantar bahasa Inggris. Kata kunci adalah "ketamin", "midazolam", "intravenous sedation", "efficacy", "safety". Terdapat enam artikel yang terpilih dan kemudian menjalani telaah kritis untuk menentukan apakah artikel tersebut sahih, penting dan dapat diterapkan pada pasien. Level of evidence ditentukan berdasarkan klasifikasi yang dikeluarkan oleh Oxford Centre for Evidence-based Medicine. ${ }^{3}$

\section{Hasil penelusuran literatur}

1. Sebuah uji klinis acak tersamar ganda dilakukan pada tahun 2004 di Turki untuk membandingkan efektivitas dan keamanan kombinasi ketamin/ midazolam dibandingkan ketamin tunggal sebagai sedasi selama tindakan pungsi lumbal pada anak. Jumlah subjek 99 anak, berusia 2 hingga 14 tahun, dibagi menjadi dua kelompok yaitu kelompok yang mendapat ketamin dengan dosis 1 miligram per kilogram $(\mathrm{mg} / \mathrm{kg})$ dan kelompok kombinasi mendapat midazolam diberikan dosis $0,1 \mathrm{mg} /$ kg selama 1-2 menit dilanjutkan dengan ketamin dosis $1 \mathrm{mg} / \mathrm{kg}$. Penambahan ketamin $0,5 \mathrm{mg} / \mathrm{kg}$ dilakukan apabila anak belum tersedasi dalam waktu 5 menit selama prosedur dilakukan. Awitan sedasi secara signifikan lebih singkat pada kelompok kombinasi yaitu 2,6 menit dibandingkan kelompok tunggal 3,4 menit (nilai $\mathrm{p}=0,01$ ). Kelompok kombinasi tidak ada yang membutuhkan dosis tambahan ketamin, sedangkan pada kelompok tunggal terdapat dua subjek yang membutuhkan dosis tambahan ketamin. Insiden efek samping tidak berbeda antara kelompok tunggal dan kombinasi (nilai $\mathrm{p}=0,88$ ). Rerata waktu pulih pada kelompok tunggal 12 menit, sedangkan pada kelompok kombinasi 15 menit $(\mathrm{p}=0,16)$. Seluruh kelompok kombinasi mengalami amnesia total, sedangkan pada kelompok tunggal 80,3\% subjek $(\mathrm{p}=0,001)$. Nyeri pasca tindakan dialami pada 4,2\% subjek dari kelompok kombinasi dan 9,8\% subjek kelompok tunggal $(\mathrm{p}=0,24)$. Nightmarel crying spell lebih sering pada kelompok tunggal $(19,6 \%)$ dibandingkan kelompok kombinasi $(6,3 \% ; p=0,04)$. Kepuasan orangtua secara signifikan lebih tinggi pada kelompok kombinasi $(\mathrm{p}=0,001)$. Dilli $\mathrm{dkk}^{4}$ menyimpulkan bahwa 
penambahan midazolam pada ketamin tidak menambah efek samping dan kombinasi ini lebih superior dibandingkan ketamin tunggal (Level of evidence 1b).

2. Penelitian kohort prospektif dilakukan pada tahun 1999 di Hong Kong mendapatkan 369 operasi minor pada anak berusia di bawah 18 tahun yang dilakukan dengan sedasi ketamin $1 \mathrm{mg} / \mathrm{kg}$ dan midazolam $0,1 \mathrm{mg} / \mathrm{kg}$. Semua pasien dapat tersedasi dalam waktu 2 menit. Dilaporkan 69\% pasien mencapai sedasi dalam waktu kurang dari 30 detik, sedangkan $75 \%$ operasi sudah selesai dengan dosis inisial ketamin $1 \mathrm{mg} / \mathrm{kg}$ dan midazolam 0,1 $\mathrm{mg} / \mathrm{kg}$. Rerata dosis ketamin $1,26 \mathrm{mg} / \mathrm{kg}$ dan midazolam $0,13 \mathrm{mg} / \mathrm{kg}$. Rerata waktu pulih yaitu 87 menit (bervariasi antara 10 sampai 360 menit). Pada 46,3\% prosedur tidak terjadi efek samping. Anak lelaki lebih besar kemungkinan mengalami agitasi selama pemulihan ( $\mathrm{p}=0,019)$. Efek samping terkait dosis pada pemberian ketamin yaitu mual dan muntah $(\mathrm{p}=0,006)$, takikardi $(\mathrm{p}=0,008)$, desaturasi $(\mathrm{p}=0,013)$, dan agitasi selama pemulihan $(\mathrm{p}=0,03)$, sedangkan pada midazolam yaitu takikardi $(\mathrm{p}=0,035)$ dan desaturasi $(\mathrm{p}=0,001)$. Cheuk $\mathrm{dkk}^{5}$ menyimpulkan bahwa kombinasi ketamin/midazolam dapat menjadi pilihan sedasi yang cepat, efektif, dan aman bagi anak yang akan menjalani berbagai tindakan operasi minor (Levels of evidence $2 b$ ).

3. Penelitian kohort retrospektif tahun 2004 di India dilakukan pada 55 tindakan prosedur onkologi anak menggunakan sedasi kombinasi ketamin/ midazolam. Penelitian ini bertujuan untuk menilai keberhasilan sedasi dan insiden komplikasi. Semua pasien mengalami amnesia total dan tidak ada yang mengeluhkan nyeri pasca tindakan. Tidak ada pasien maupun orang tua yang menunjukkan atau mengeluhkan rasa cemas berhubungan dengan rencana prosedur atau sedasi berikutnya. Efek samping terjadi pada $27 \%$ subjek berupa penurunan saturasi oksigen sementara, muntah, dan rasa pusing. Semua efek samping dapat diatasi dengan cepat dan mudah ${ }^{6}$ (Levels of evidence $2 b$ ).

4. Penelitian kohort retrospektif pada tahun $2001 \mathrm{di}$ Jerman melibatkan 63 subjek yang menjalani 183 prosedur invasif. Sedasi dimulai dengan midazolam $0,1 \mathrm{mg} / \mathrm{kg}$ satu menit sebelum pemberian ketamin dilanjutkan dengan ketamin $1 \mathrm{mg} / \mathrm{kg}$. Pemberian dosis tambahan ketamin $0,33 \mathrm{mg} / \mathrm{kg}$ diberikan jika pasien belum tersedasi atau bila prosedur yang diperlukan membutuhkan waktu lebih panjang. Rerata dosis ketamin yang dibutuhkan yaitu 1,4 $\mathrm{mg} / \mathrm{kg}$. Rerata awitan kerja obat 2 menit, rerata waktu tindakan 7 menit, dan rerata waktu pulih 45 menit. Dosis ketamin secara positif berkorelasi dengan durasi prosedur invasif $(r=0,483 ; \mathrm{p}<0,01)$ dan waktu pulih $(r=250, p<0,1)$. Semua prosedur dapat berjalan baik dan pasien dapat pulang pada hari yang sama. Empat prosedur (2\%) yang mengalami emergencelfrightening reaction. Efek samping terjadi pada 33 prosedur $(18 \%$, interval kepercayaan 12,8-24,4). Efek samping yang paling sering terjadi adalah penurunan saturasi oksigen yang dapat kembali secara spontan atau dengan mengubah posisi bila leher tertekuk ${ }^{7}$ (Levels of evidence 2b).

5. Penelitian kohort prospektif dilakukan di Turki pada 115 subjek yang menjalani 237 prosedur infasif menggunakan sedasi dengan midazolam 0,1 $\mathrm{mg} / \mathrm{kg} / \mathrm{kali}$ (dosis maksimum $10 \mathrm{mg}$ ) dilanjutkan ketamin $1 \mathrm{mg} / \mathrm{kg} / \mathrm{kali}$ (dosis maksimum $100 \mathrm{mg}$ ). Rerata waktu sedasi yaitu 24 detik dan rerata waktu pulih yaitu 28 menit. Tidak diperlukan penambahan dosis obat pada $87 \%$ prosedur. Tidak terdapat apnea, depresi napas, dan efek samping berat lainnya. Terdapat peningkatan tekanan darah sistolik dan diastolik, laju jantung, dan laju napas selama sedasi, namun semua nilai tersebut kembali normal setelah prosedur selesai $(\mathrm{p}<0,01)$, peningkatan tersebut tidak bermakna secara klinis dan menghilang setelah pemulihan ${ }^{8}$ (Levels of evidence 2b).

6. Penelitian kohort retrospektif dilakukan pada tahun 1999 hingga 2003 di Turki pada anak berusia di bawah 18 tahun yang memerlukan prosedur menggunakan sedasi di luar ruang operasi. Dosis midazolam yaitu $0,05 \mathrm{mg} / \mathrm{kg}$ (maksimum 2,5 mg) dilanjutkan dengan ketamin dosis inisial $(1 \mathrm{mg} /$ $\mathrm{kg})$. Dosis ketamin kedua $(0,5-1 \mathrm{mg} / \mathrm{kg})$ diberikan 3 menit setelah sedasi bila sedasi dalam belum tercapai. Selama prosedur semua pasien tersedasi dengan rerata dosis ketamin $1,8 \mathrm{mg} / \mathrm{kg}$. Hanya $23 \%$ prosedur yang membutuhkan ketamin lebih dari $2 \mathrm{mg} / \mathrm{kg}$. Rerata waktu pulih 16 menit. Selama periode pemulihan, hanya $1,1 \%$ subjek yang mengalami fenomena pulih sadar pasca pemberian ketamin. Hasil penelitian ini menunjukkan sedasi menggunakan ketamin/midazolam merupakan 
metode yang aman dan efektif bagi anak yang akan menjalani prosedur invasif' (Levels of evidence $2 b$ ).

\section{Pembahasan}

Ketamin adalah derivat phencyclidine yang meng hasilkan anestesia disosiatif. ${ }^{10}$ Mekanisme kerja yang menghasilkan efek analgesi yaitu ikatan dengan reseptor $N$-methyl-D-aspartate (NMDA) sebagai antagonis non kompetitif. Ketamin juga dapat berikatan dengan reseptor lain, seperti reseptor opioid dan muskarinik. Mekanisme kerja yang berhubungan dengan kondisi anestesi dan halusinasi yaitu menghambat ambilan dopamin sehingga meningkatkan kadar sinaptik dopamin. ${ }^{11}$ Ketamin mencapai konsentrasi puncak plasma dalam waktu 1 menit setelah pemberian intravena. Lama kerja ketamin antara 5 sampai 25 menit, sedangkan waktu paruh 2 hingga 3 jam. Dosis ketamin intravena $1-2 \mathrm{mg} / \mathrm{kg} / \mathrm{kali}$ dengan dosis maksimal 50 mg. ${ }^{11}$ Kelebihan utama ketamin terletak pada aktifitas sedasi dan analgesia, kestabilan kardiovaskular dan efek samping minimal terhadap pernapasan. Namun, ketamin memiliki beberapa efek samping yang kurang disukai seperti menyebabkan mimpi buruk, halusinasi, dan reaksi yang tidak menyenangkan yang disebut dengan fenomena pulih sadar pasca pemberian ketamin. Pada dosis tinggi ketamin dapat menimbulkan aktivitas eksitatori pada sistem talamus dan limbik. ${ }^{12,13}$

Midazolam adalah golongan benzodiazepin larut air yang memiliki cincin imidazol. Awitan kerja obat 1 hingga 3 menit, waktu paruh distribusi 6 hingga 15 menit, dan waktu paruh 1,5 sampai 2 jam. ${ }^{10,14}$ Efek amnesia pada midazolam lebih poten daripada efek sedasi sehingga pasien dapat tetap terjaga namun tetap dalam keadaan amnesia terhadap suatu percakapan atau kejadian. Dosis intravena pada anak 0,05-0,1 mg/kg. Benzodiazepin bekerja dengan cara memfasilitasi kerja gamma-aminobutyric acid (GABA) yang merupakan neurotransmitter inhibisi utama pada SSP. Rangsangan GABA pada reseptor GABA menyebabkan neuronneuron pasca-sinaps menjadi lebih resisten terhadap rangsangan eksitasi sehingga menghasilkan efek anti cemas, sedasi, anterograde amnesia, dan anti kejang. ${ }^{15}$ Anterograde amnesia merupakan efek yang paling diharapkan dari midazolam karena menyebabkan pasien tidak dapat mengingat prosedur traumatik yang sedang dijalani. ${ }^{10}$ Kekurangan midazolam yaitu menyebabkan depresi napas. Kejadian henti napas dapat terjadi pada pemberian dalam dosis besar (di atas $0,3 \mathrm{mg} / \mathrm{kg}$ ). ${ }^{5}$

Ketamin maupun midazolam terbukti efektif ketika digunakan sebagai obat tunggal untuk sedasi dan analgesi, tetapi terdapat beberapa variasi respon sedasi dan efek samping dari masing-masing obat. Maka perlu dipikirkan kombinasi obat yang dapat meniadakan atau mengurangi efek samping obat lain. ${ }^{6,7,9}$ Selain itu, kombinasi beberapa obat dilakukan untuk meningkatkan kualitas sedasi dan mengurangi kebutuhan dosis obat sedasi. Kombinasi ketamin/ midazolam mulai digunakan secara luas pada populasi anak. ${ }^{4}$ Namun penelitian khusus mengenai efektivitas dan keamanan obat ini pada tindakan prosedur hematologi-onkologi masih terbatas.

Berdasarkan enam penelitian yang dibahas, didapatkan awitan sedasi lebih singkat pada kelompok kombinasi dengan rerata waktu sedasi kurang dari 30 detik. ${ }^{2,4,5}$ Penambahan midazolam sebelum pemberian ketamin memberikan efek amnesia total dan mengurangi keluhan nyeri pasca-prosedur. Rerata waktu pulih pada kelompok tunggal 12 menit, sedangkan pada kelompok kombinasi bervariasi antara 15 menit hingga 28 menit. Kombinasi ketamin/ midazolam menghasilkan efek sedasi yang baik dengan dosis yang lebih rendah, penggunaan dosis tambahan untuk ketamin dapat berkurang jika digunakan dengan kombinasi midazalam. ${ }^{16}$ Efek samping secara umum tidak berbeda antara kelompok tunggal dan kombinasi. 4,5 Mimpi buruk lebih sering terjadi pada kelompok tunggal dibandingkan kelompok kombinasi. ${ }^{4}$ Selama periode pemulihan setelah sedasi menggunakan sedasi kombinasi, hanya $1,1 \%$ subjek yang mengalami fenomena pulih sadar pasca pemberian ketamin. ${ }^{9}$ Kepuasan orangtua secara signifikan lebih tinggi pada kelompok kombinasi $(\mathrm{p}=0,001)$ dan tidak ada pasien ataupun orangtua yang mengeluhkan rasa cemas berhubungan dengan prosedur atau sedasi berikutnya. ${ }^{6}$

\section{Kesimpulan dan saran}

- Pemberian midazolam sebagai premedikasi sebelum pemberian ketamin memiliki kemanfaatan dan keamanan yang lebih baik dibandingkan ketamin tunggal terutama dalam tercapainya awitan sedasi dan menurunkan kejadian fenomena pulih sadar pasca pemberian ketamin. Selain itu 
Murti Andriastuti dkk: Efektivitas dan keamanan kombinasi ketamin/midazolam dibandingkan ketamin tunggal sebagai sedasi

midazolam mempunyai efek anterograde amnesia sehingga mengurangi efek traumatik pascatindakan baik pada anak maupun orangtua.

- Perlu dipertimbangkan penggunaan midazolam sebagai premedikasi sebelum pemberian ketamin sebagai sedasi pada tindakan aspirasi sumsum tulang atau kemoterapi intratekal.

- Ketamin memilki efek anestesia disosiatif yang dapat dihilangkan dengan pemberian obat premedikasi midazolam sehingga penambahan midazolam dapat meningkatkan kepuasaan klinisi dan orangtua.

\section{Daftar pustaka}

1. Challenges in paediatric procedural sedation : political, economic, and clinical aspects. Br J Anaesth 2014;113:48-62.

2. Gelen SA, Sarper N, Demirsoy U, Zengin E, Cakmak E. The efficacy and safety of procedural sedoanalagesia with midazolam and ketamine in pediatric hematology. Turk J Hematol 2015:32:351-4.

3. Oxford Centre of Evidence-Based Medicine 2011 Levels of Evidence [diakses 15 Juni 2016]. Didapat dari: http:// www.cebm.net/wp-content/uploads/2014/06/CEBM-Levels-ofEvidence-2.1.pdf2011

4. Dilli D, Dallar Y, Sorgui NH. Intravenous ketamin plus midazolam vs. intravenous ketamin for sedation in lumbar puncture: a randomized controlled trial. Indian Pediatr 2008;45:899-904.

5. Cheuk D, Wong W, Ma E, Lee TL, Ha SY, Lau YL, dkk. Use of Midazolam and ketamin as sedation for children undergoing minor operative procedures. Support Care Cancer. 2005;13:1001-9.

6. Borker A, Ambulkar I, Gopal R, Advani SH. Safe and efficacious use of procedural sedation and analgesia by nonanesthesiologists in a pediatric hematology-oncology unit. Indian Pediatrics 2006;43:309-14.
7. Meyer S, Aliani S, Graf N, Reinhard H,Gottschling S. Sedation with midazolam and ketamine for invasive procedures in children with malignancies and hematological disorder: a prospective study with reference to the symphatomimetic properties of ketamine. J Pediatr Hematol Oncol 2003;20:291301.

8. Gelen SA, Sarper N, Demirsoy U, Zengin E, Cakmak E. The efficacy and safety of procedural sedoanalagesia with midazolam and ketamine in pediatric hematology. Turk J Hematol 2015:32:351-4.

9. Karapinar B, Yilmaz D, Demirag K, Kantar M. Sedation with intravenous ketamin and midazolam for painful procedures in children. Pediatr Int 2006;48:146-51.

10. Meredith JR, O'Keefe K, Galwankar S. Pediatric procedural sedation and analgesia. J Emerg Trauma Shock 2008;2:88-96.

11. Traivaree C, Jindakam W, Monsereenusorn, Rujkijyanont P, Lumkul R. The factors of ketamine that affect sedation in children with oncology procedures: parent satisfaction perspective. J Med Assoc Thai 2014;97:19-24.

12. Gazal G, Fareed WM, Zafar MS, Al-Samadani KH. Pain and anxiety management for pediatric dental procedures using various combination of sedative drugs: a review. Saudi Pharm J 2016;24:379-85.

13. Karapinar B, Yilmaz D, Demirag K, Kantar M. Sedation with intravenous ketamin and midazolam for painful procedures in children. Pediatr Int 2006;48:146-51.

14. Sajedi P, Habibi B. Comparison of the effect of intravenous premedication: midazolam, ketamine, and combination of both on reducing anxiety in pediatric patients before general anesthesia. J Res Pharm Pract 2015;4:187-92.

15. Sievers TD, Yee JD, Foley ME, Blanding PJ, Berde CB. Midazolam for conscious sedation during pediatric oncology procedures: safety and recovery parameters. Pediatrics 1991;88:1172-9.

16. Kaviani N, Ashrafi S, Jabbarifar SE, Ghaffari E. The efficacy of two intravenous sedative drugs in management of uncooperative children for dental treatment. J Dent Shiraz Univ Med Sci 2015;16:29-34. 